\title{
Categorization and normalization of vowels by 3-year-old children
}

\author{
CATHY A. KUBASKA \\ Indiana University, Bloomington, Indiana \\ and \\ RICHARD N. ASLIN \\ University of Rochester, Rochester, New York
}

\begin{abstract}
A two-alternative, forced-choice procedure was used in two experiments to test 3-year-old children's categorization of natural vowel tokens produced by several talkers. An appropriate pointing response (right or left) was visually reinforced with one of two television displays. In Experiment 1 , the stimuli were isolated tokens of $/ \mathrm{a} /$ and $/ \mathrm{i} /$ produced by a male adult, a female adult, a male child, and a female child. In Experiment 2, the stimuli were isolated tokens of / a/ and $/ \mathrm{N}$ produced by the same talkers. In both experiments, 3-year-olds spontaneously generalized their pointing responses from the male adult vowel tokens to the corresponding vowels produced by the other talkers. Children reinforced for an arbitrary grouping of the two vowel categories persisted in categorizing on the basis of vowel quality. Results from both experiments demonstrate the presence of perceptual constancy for vowel tokens across talkers. In particular, the results from Experiment 2 provide evidence for normalization of isolated, quasi-steady-state vowel tokens because the formant values for tokens of $/ \mathrm{N}$ produced by the woman and the two children were closer to the formant frequencies of the male adult's /æ/ than to the male adult's $/ \mathrm{N}$.
\end{abstract}

It has been known for over 30 years that the first two formants of a vowel are important acoustic cues to its phonetic identity (Delattre, Liberman, Cooper, \& Gerstman, 1952). However, theories of vowel perception are complicated by the fact that the formant frequencies of a given vowel vary widely within and across talkers (Peterson \& Barney, 1952) due to differences in context, speaking rate, and vocal tract dimensions (Shankweiler, Strange, \& Verbrugge, 1977). Despite this variability, listeners are able to identify accurately vowels that are produced by different talkers under a variety of experimental conditions, including vowels in consonantal contexts (Diehl, McCusker, \& Chapman, 1981; Strange \& Gottfried, 1980; Strange, Verbrugge, Shankweiler, \& Edman, 1976; Verbrugge, Strange, Shankweiler, \& Edman, 1976), vowels in isolation (Assmann, Nearey, \& Hogan, 1982; Diehl et al., 1981; Macchi, 1980), gated vowel centers (Assmann

The results reported in this paper were previously presented at the 105th and 106th meetings of the Acoustical Society of America. We thank David Pisoni for providing the use of the Speech Research Laboratory for processing our speech stimuli. We also thank Jerry Forshee for software development, David Link for hardware support, Mary Buuck for assistance in running subjects, and Howard Nusbaum and Sandra Shea for their helpful comments. This research was supported by NIH Training Grant NS07134 to Indiana University and by NICHHD Research Grant HD11915 and NICHHD Research Career Development Award HD00309 to R. N. Aslin. Cathy A. Kubaska is now at AT\&T Consumer Products, Indianapolis. Reprint requests should be addressed to: Richard N. Aslin, Department of Psychology, University of Rochester, Rochester, NY 14627. et al., 1982), and syllables from which the steady-state portion of the vowel has been deleted (Jenkins, Strange, \& Edman, 1983; Parker \& Diehl, 1984; Strange, Jenkins, \& Johnson, 1983).

Theories of vowel perception have emphasized the importance of the information from either the steady-state formant frequencies or the dynamic cues distributed throughout the syllable. These two theories have been referred to as "target normalization" and "dynamic specification" by Strange et al. (1983). Target normalization theories use the steady-state formant values of the vowel as input to a normalization process by which the vowel is categorized appropriately in the vowel space (Gerstman, 1968; Joos, 1948; Lieberman, 1973; Nearey, 1977, 1983). Other researchers (Shankweiler et al., 1977; Strange, Edman, \& Jenkins, 1979; Strange et al., 1983; Verbrugge et al., 1976) have stressed the role of dynamic spectral cues in vowel perception. According to this dynamic specification theory, steady-state formant information is considered a sufficient, though not necessary, cue for vowel identification (Strange \& Gottfried, 1980). The listener uses the acoustic information distributed throughout the syllable, including consonant formant transitions and vowel duration, to identify the vowel. The results of studies that show lower error rates in identification for vowels in syllable context versus vowels in isolation are taken as evidence in support of dynamic specification theories (Gottfried \& Strange, 1980; Strange \& Gottfried, 1980; Strange et al., 1976; Verbrugge et al., 1976). Additional evidence supporting this position comes from 
studies demonstrating accurate vowel identification for syllables lacking steady-state vowel segments (Jenkins et al., 1983; Parker \& Diehl, 1984; Strange et al., 1983).

An important question in developmental speech research is whether infants and young children perceive the similarity of phonetically equivalent but acoustically different vowels spoken by different talkers. Using an operant headturning procedure, Kuhl (1979) obtained results that suggested that 6-month-old infants do have perceptual constancy for certain vowel categories. The stimuli were synthetic tokens of the vowels /a/ and /i/ with formant parameters appropriate for a male adult, a female adult, and a child talker. Also, each token was synthesized with either a rising or a rising-falling pitch contour. The infants learned a headturning response to one of the male adult vowels with a rising-falling contour and later transferred this response to presentations of the same vowel produced by the female adult and by the child, as well as to the male adult token with a rising contour. In doing so, the infants ignored the variations in talker and intonation contour present in the stimuli.

Kuhl (1983) obtained similar results for synthetic tokens of $/ a /$ and $/ \mathrm{J} /$ with formant parameters appropriate for a male adult, a female adult, and a child talker. This vowel contrast was chosen because $/ a /$ and $/ \mathrm{J} /$ share similar spectral patterns. Kuhl also noted Peterson and Barney's (1952) results, which indicated that the formant frequencies for tokens of $/ a /$ and $/ \mathrm{J} /$ produced by different talkers might show vowel category overlap. For example, due to differences in vocal tract size and shape, tokens of $/ a /$ produced by male adults often have first and second formant frequencies (F1 and F2) that extend into the F1-F2 space of tokens of $/ 2 /$ produced by women and young children. Despite this acoustic overlap, adult listeners are able to identify correctly the vowels' phonemic category, presumably through a normalization process. Because Kuhl's study was not designed as a test of vowel normalization, spectrally similar, but nonoverlapping, formant parameters were chosen for the stimuli in her study (see Figure 1A). As in the /a/-/i/ study, 6-month-old infants transferred a head-turning response from one of the male adult $/ \mathrm{a} /$ or $/ \mathrm{J} /$ tokens to a set of new tokens of the same vowel varying in talker and intonation contour. Again, the infants ignored the irrelevant acoustic variations while generalizing the headturning response to the appropriate stimuli. It should be noted that a normalization process was not needed to accomplish this task because the vowel tokens did not have overlapping formant frequencies. Thus, the infants in this study could have responded appropriately simply on the basis of acoustic similarity.

In another study, Kuhl and Miller (1982) used a highamplitude sucking procedure to examine 1- to 4-monthold infants' discrimination of changes in vowel quality and pitch contour. When only one of these components was altered after a preshift habituation period, evidence for discrimination was obtained. However, when both components were altered, infants provided evidence for detection of changes in vowel target but not in intonation.

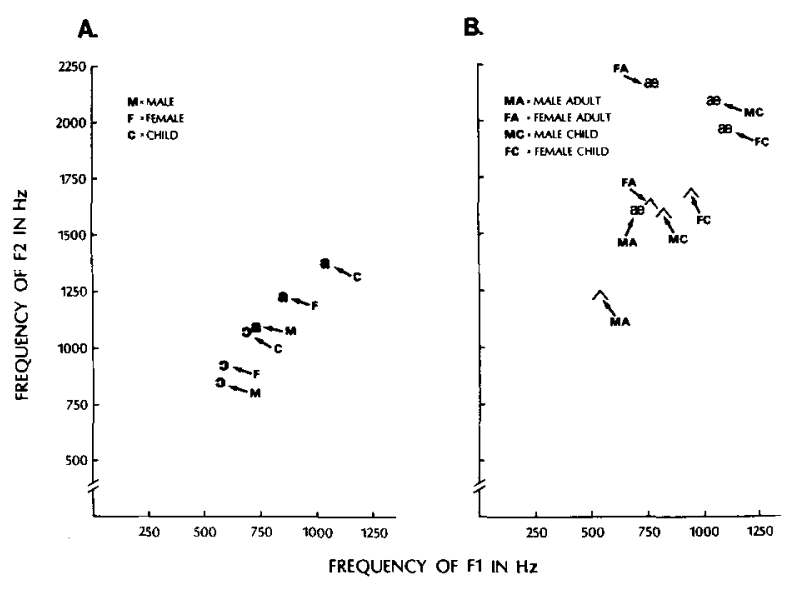

Figure 1. (A) F1 and F2 values for the synthetic vowel tokens of $/ a /$ and /o/ used in Kuhl's (1983) study. (B) F1 and F2 values for the natural vowel tokens of $/ æ /$ and $/ \mathrm{A} /$ used in Experiment 2.

Also, infants did not provide evidence of discriminating stimulus changes when vowel quality and pitch contour were recombined into novel targets after a preshift habituation period in which the stimuli varied on both dimensions. Kuhl and Miller also measured the amount of time required by infants to habituate to the preshift stimuli. Generally, infants took longer to meet the habituation criterion during preshift periods with two stimuli. However, when the habituation period contained two or more stimuli with the same vowel quality, the time to habituation was not significantly different from preshift periods with only one stimulus. The results of these discrimination experiments by Kuhl and her colleagues show that young infants appear to recognize some similarity between members of certain vowel categories, despite differences in intonation and talker, and that vowel quality seems to be a particularly salient perceptual dimension for young infants.

Other researchers (e.g., Aslin, Pisoni, \& Jusczyk, 1983) have noted that stronger conclusions could be made about infants' perceptual constancy for speech sounds with a procedure that measured categorization directly. For example, if infants could be trained to make a leftward headturn to one stimulus and a rightward headturn to a second stimulus, one could determine whether a third stimulus was perceived as more similar to the first ("left") or to the second ("right") stimulus. Unfortunately, researchers attempting to develop such a two-alternative headturning procedure have met with considerable difficulty (Aslin, Perey, Hennessy, \& Pisoni, 1977; Katz \& Jusczyk, 1980), particularly for speech sounds containing subtle acoustic differences. This lack of success is undoubtedly due, in part, to the fact that the task requirements of a two-alternative categorization task with discrete trials are considerably more complex than those of a discrimination procedure in which the subject must respond only to changes in a category of randomly varying tokens. For example, in Kuhl's (1983) study, infants were transferred from a simple two-token discrimination task to a 
task in which several different background tokens were presented. Infants who made a headturn to these discriminably different background tokens learned, through the absence of reinforcement, that certain acoustic variations were not relevant to the task. Thus, this categorization procedure is essentially a selective habituation task with greatly reduced demands on memory and/or associative learning compared to a two-alternative categorization task.

In the present study, we tested 3-year-old children's categorization of natural vowel tokens produced by several talkers using a two-alternative, forced-choice procedure. In the first experiment, the stimuli were isolated tokens of /a/ and /i/ produced by a male adult, a female adult, a male child, and a female child. The stimuli in the second experiment were isolated tokens of $/ æ /$ and $/ \mathrm{N} /$ produced by the same talkers. This second contrast was chosen because the formant values for tokens of $/ \Lambda /$ produced by the woman and the two children overlapped the formant frequencies of the male adult's $/ æ /$. One could argue from the relatively sophisticated speech production skills of 3-year-olds that vowel normalization must be operative at this early age. However, it is important to emphasize that both dynamic spectral information and semantic context are absent in this categorization task. It is quite likely that very young children rely heavily on prosody and nonphonemic information, such as situational context and gestures, to extract the meaning of words, particularly since identification of minimal pairs is rarely required of the listener in the natural environment. Furthermore, studies have shown that young children more accurately identify speech sounds that contain redundant acoustic cues to specific phonemic contrasts (Greenlee, 1978,1980 ). When required to base their identification on minimal acoustic information, young children perform less accurately. Thus, it might be expected that young children would have difficulty with this categorization task, particularly with the $/ \mathfrak{Z} /-/ \mathrm{A} /$ contrast, because the cues from formant transitions and inherent vowel duration are absent. The elimination of these cues made possible the assessment of vowel normalization of isolated, quasisteady-state vowel tokens by 3-year-olds.

\section{EXPERIMENT 1}

The first study was conducted to evaluate our procedures for assessing 3-year-olds' categorization of the two acoustically distinct vowels /a/ and /i/. Previous studies of speech perception in young children used a twoalternative, forced-choice procedure that typically involved a picture identification task (Greenlee, 1980; Krause, 1982; Simon \& Fourcin, 1978; Strange \& Broen, 1981). For example, Simon and Fourcin (1978) examined 2- to 14-year-old children's perception of a voiced/voiceless contrast when voice onset time (VOT) and firstformant (F1) onset were varied. The younger subjects in this experiment pointed to one of two pictures, each depicting an item from a minimal pair differing only in the initial stop consonant. Using an almost identical procedure, Strange and Broen (1981) tested 3-year-old children's perception of the $/ \mathrm{w} /-/ \mathrm{r} /$ and $/ \mathrm{r} /-/ 1 /$ contrasts. In the present study, subjects also learned a two-alternative, forced-choice task, but the procedure was adapted to assess categorization in young children without using any picture referents. ${ }^{1}$

\section{Method}

Subjects. The subjects in this study were 203 -year-old children from the Bloomington, Indiana, area, ranging in age from 2 years 10.5 months to 3 years 0.75 months with a mean age of 2 years 11.75 months. Their names were obtained from birth announcements in the local newspaper, and their parents were solicited by mail and a follow-up telephone call. Subjects were tested twice a week for a total of four to five sessions and were paid $\$ 3$ per session. An additional 17 subjects were dropped after completing two or more sessions because of illness (3), scheduling conflicts (2), child's fear of the sound-attenuated booth (1), or inability to reach the testing criterion on the two training stimuli (11). ${ }^{2}$

Stimuli. Isolated tokens of the vowels $/ \mathrm{a} /$ and $/ \mathrm{i} /$, spoken by a male adult, a female adult, a male child (age 12), and a female child (age 10), were produced in a single-walled, sound-attenuated booth (I.A.C. Model 401A) and recorded with an Ampex AG-500 tape recorder and an Electro-Voice D054 microphone. These stimuli were low-pass filtered at $4.8 \mathrm{kHz}$, digitized at a sampling rate of $10 \mathrm{kHz}$, and stored on computer disk. A digital waveform editing program (Luce \& Carrell, 1981) was used to set the duration of all vowel tokens at approximately $300 \mathrm{msec}$, with the constraint that the vowel endpoints be placed at the zero crossing corresponding to the end of a complete pitch period. Segments were deleted at the end of the vowel tokens to control for duration. The amplitude of these tokens was also equated with a waveform modification program (Bernacki, 1981). All stimuli were presented at $63 \pm 2 \mathrm{~dB}$ SPL, as verified with a Triplett sound-level meter (Model 370, C scale). Transients at the onset of the stimuli were eliminated by gradually increasing the amplitude of the initial $20 \mathrm{msec}$ of a token with a ramping function in the waveform modification program. Similarly, offset transients were eliminated by gradually decreasing the amplitude of the final $20 \mathrm{msec}$ of each token. The formant frequencies were also measured at the midpoint of each stimulus with a spectral analysis program (Kewley-Port, 1978), and these values are listed in Table 1 . In cases where accurate measurements could not be obtained with this program's formant tracking algorithm, a second program, which allowed manual formant tracking (Carrell, 1984), was used to determine these values. Finally, the mean fundamental frequency of each token was measured using a pitch tracking program (Smith, 1981). These values are listed with the formant frequency measurements in Table 1 .

Apparatus. A schematic of the testing apparatus is shown in Figure 2. The child was seated on the parent's lap in one corner

Table 1

Formant Frequency Values for Stimuli in Experiment 1

\begin{tabular}{lrrrr}
\hline \multicolumn{1}{c}{ Talker } & F0 & \multicolumn{1}{c}{ F1 } & F2 & F3 \\
\hline Male Adult $/ \mathrm{a} /$ & 98 & 653 & 1058 & 2339 \\
Male Adult $/ \mathrm{i} /$ & 103 & 327 & 2104 & 3097 \\
Fernale Aduit $/ \mathrm{a} /$ & 182 & 1076 & 1678 & 2871 \\
Female Adult $/ \mathrm{i} /$ & 191 & 384 & 2762 & 3465 \\
Male Child $/ \mathrm{a} /$ & 261 & 1070 & 1545 & 2927 \\
Male Child $/ \mathrm{i} /$ & 292 & 315 & 2942 & 4022 \\
Female Child $/ \mathrm{a} /$ & 228 & 1232 & 1485 & 3696 \\
Female Child $/ \mathrm{i} /$ & 222 & 429 & 3349 & 3955 \\
\hline
\end{tabular}




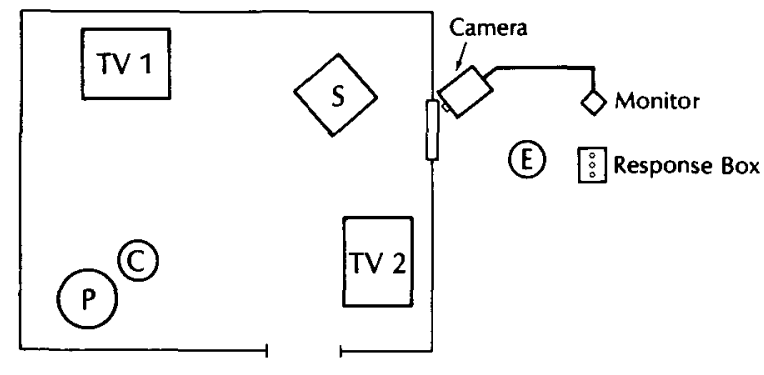

TWO AFC BOOTH ARRANGEMENT

Figure 2. Schematic of the testing apparatus used in both experiments. $\mathbf{C}=$ child; $\mathbf{P}=$ parent; $\mathbf{E}=$ experimenter; $\mathbf{S}=$ speaker.

of a single-walled, sound-attenuated booth (I.A.C. Model 402). The test stimuli were presented over a loudspeaker (Radio Shack MC1000 ) positioned in front of the child. Two color television sets (12-in. RCA XL-100) were located in the remaining corners of the booth. The child was trained to point to one television when a particular vowel was heard and to the second television when another vowel was heard. If the correct pointing response was made, the television came on and displayed an 8-sec segment of the "Muppet Movie," or some other film, via an RCA Selectavision video disk player. During the testing sessions, the parent listened to masking music over headphones to eliminate any bias. A camera was mounted outside the booth near a concealed window, and the experimenter observed the child's responses on a TV monitor, scoring the directional responses with a button box. During the testing sessions, the experimenter was unaware of the specific stimulus that was being presented. She simply initiated trials when the child was sitting still and scored the direction in which the child pointed. Stimulus presentation and reinforcement were controlled by a PDP-11/34 computer. The stimuli were presented to subjects on-line via a 12-bit D/A converter with a sampling rate of $10 \mathrm{kHz}$, and were low-pass filtered at $4.8 \mathrm{kHz}$.

Procedure. The general procedure included three phases: shaping, testing, and categorization. During shaping sessions, all subjects were trained to point to one TV upon hearing one male adult vowel token and to the other TV upon hearing the second male adult vowel token. The pairing of TVs and vowels was counterbalanced across subjects. During the shaping sessions, parents did not wear headphones and encouraged their children to point to the appropriate TV when each of the two vowels was presented. The experimenter controlled the presentation of one of the two stimuli on each trial, which consisted of the repetitive presentation of a given vowel with an interstimulus interval of $1.5 \mathrm{sec}$. Each trial was terminated by the experimenter's buttonpress indicating a pointing response or by a total of 20 repetitions of the vowel. The child was reinforced on every trial, provided that the correct pointing response was made, even if it was preceded by an incorrect response.

A subject proceeded to the testing phase when the experimenter judged that the child's first pointing response was consistently correct, generally after one or two 10-min sessions. During the testing sessions, parents wore headphones and listened to masking music while their children responded to the male adult's vowel tokens. The choice of the vowel stimulus and the presentation of reinforcement in this phase was now computer controlled. In these testing sessions, the subject was required to point in the correct direction in order to view the visual reinforcer. If the initial pointing response was incorrect, the reinforcer was not presented, and another trial was not initiated until the child had ceased pointing and was sitting still. If the child responded correctly to $90 \%$ of 10 consecutive trials (no-response trials were counted as incorrect), the session immediately proceeded to the categorization phase, during which vowels produced by all four talkers were introduced on separate trials. In this last stage, a session consisted of five trials of each vowel presented in random order.

There were two experimental groups in this study. Ten subjects were assigned to the constant-vowel group, in which all tokens of /a/ were reinforced by one television and all tokens of /i/ by the other television. The pairing of TVs and vowels was counterbalanced across subjects; all tokens of $/ a /$ were assigned to the left TV for five of these subjects and to the right TV for the remaining five subjects. A representative constant-vowel stimulus set is shown in Table 2.

Another 10 subjects were assigned to the mixed-vowel group, in which each subject received a different random combination of vowels, with the constraint that two $/ \mathrm{a} / \mathrm{s}$ and two $/ \mathrm{i} / \mathrm{s}$ were paired with each TV. This second condition was a control for the possibility that children could simply memorize the specific TV-vowel associations (see, e.g., Hillenbrand, 1983). As in the constant-vowel group, the pairing of TVs and vowels was counterbalanced across subjects; five subjects were taught to associate the male adult /a/ (one of the two training stimuli) with the left TV, and the remaining five subjects to associate that token with the right TV. A representative mixed-vowel stimulus set is shown in Table 2 . Note that for all mixed-vowel stimulus sets, stimuli 2 and 6 match the vowel quality of the two training stimuli (1 and 5), whereas stimuli $3,4,7$, and 8 do not. Hereafter, stimuli $1,2,5$, and 6 will be referred to as Set 1 stimuli, and stimuli $3,4,7$, and 8 will be referred to as Set 2 stimuli.

After each subject met the testing phase criterion of $90 \%$ correct on 10 consecutive trials, data were collected in two or more sessions of the categorization phase. The results are based on the subjects' responses to 10 trials of each vowel token (i.e., at least two categorization sessions), for a total of 80 trials per subject.

\section{Results and Discussion}

Overall, subjects in the constant-vowel group responded correctly on an average of $72.5 \%$ of the trials $(\mathrm{SD}=12.2)$, while subjects in the mixed-vowel group responded correctly on only $48 \%$ of the trials $(\mathrm{SD}=8.1)$. This group difference was not simply the result of the constant-vowel subjects' learning to categorize more easily than the mixed-vowel subjects, because the mean performance on the first trial for each of the eight vowels was $70.2 \%$ and $51.3 \%$ for the constant and mixed groups, respectively. Furthermore, the chance performance of the mixed-vowel group was not the result of their forgetting the appropriate pointing responses to the training stimuli after they entered the categorization phase. The mean performance of the mixed-vowel group to the training stimuli presented during the categorization phase was $77.2 \%$ correct, a level

Table 2

Representative Stimulus Sets for Constant- and Mixed-Vowel Groups in Experiment 1

\begin{tabular}{|c|c|}
\hline Left TV & Right TV \\
\hline \multicolumn{2}{|c|}{ Constant-Vowel Group } \\
\hline $\begin{array}{l}\text { 1. Male Adult } / \mathrm{a} / \\
\text { 2. Female Adult } / \mathrm{a} / \\
\text { 3. Male Child } / \mathrm{a} / \\
\text { 4. Female Child } / \mathrm{a} /\end{array}$ & $\begin{array}{l}\text { 5. Male Adult } / \mathrm{i} / \\
\text { 6. Female Adult } / \mathrm{i} / \\
\text { 7. Male Child } / \mathrm{i} / \\
\text { 8. Female Child } / \mathrm{i} /\end{array}$ \\
\hline \multicolumn{2}{|c|}{ Mixed-Vowel Group } \\
\hline $\begin{array}{l}\text { 1. Male Adult } / \mathrm{a} / \\
\text { 2. Female Child } / \mathrm{a} / \\
\text { 3. Female Adult } / \mathrm{i} / \\
\text { 4. Male Child } / \mathrm{i} /\end{array}$ & $\begin{array}{l}\text { 5. Male Adult } / \mathrm{i} / \\
\text { 6. Female Child } / \mathrm{i} / \\
\text { 7. Female Adult } / \mathrm{a} / \\
\text { 8. Male Child } / \mathrm{a} /\end{array}$ \\
\hline
\end{tabular}




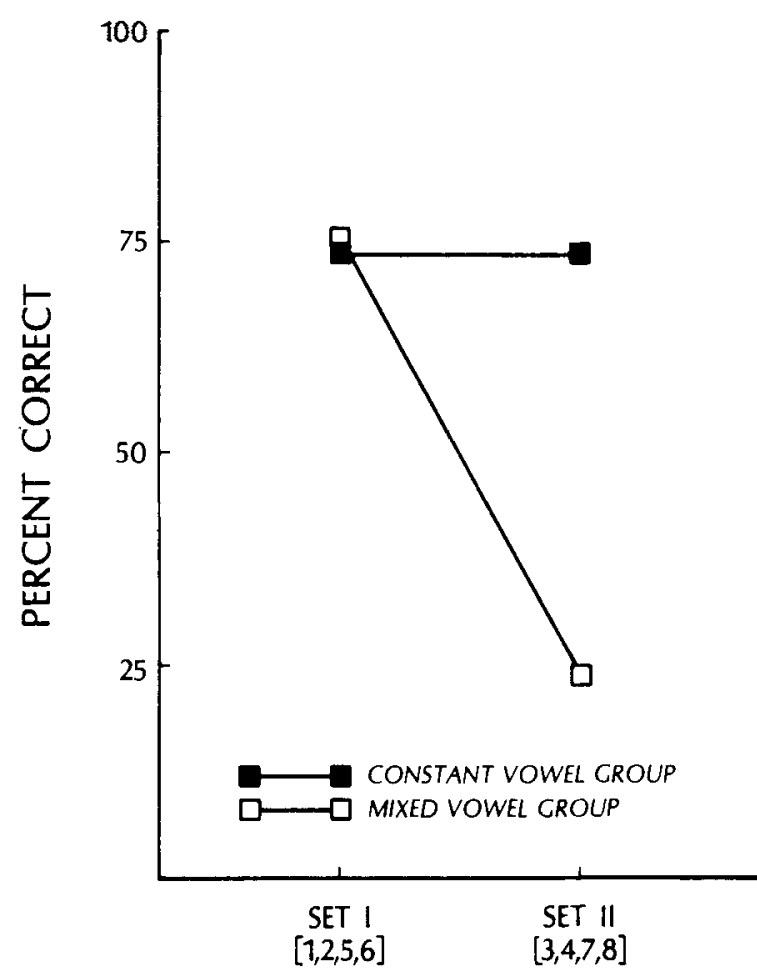

Figure 3. Mean percentage of correct responses in the constantand the mixed-vowel groups for Set 1 and Set 2 stimuli in Experiment 1.

that was significantly above $50 \%[t(9)=6.97, p<.001]$ but not significantly different from the mean of $73.8 \%$ correct for the constant-vowel group $[\mathrm{t}(18)=0.61, \mathrm{p}>$ $.05]$. Finally, as shown in Figure 3, the constant-vowel group performed at the same level for both sets of stimuli, whereas the performance of the mixed-vowel group dropped from $73.2 \%$ correct $(S D=15.9)$ for Set 1 stimuli to $23.3 \%$ correct $(\mathrm{SD}=18.3)$ for Set 2 stimuli.

A two-factor, mixed-design analysis of variance with repeated measures was used to analyze these data. There was a significant difference between the performance of the constant- and mixed-vowel groups $[\mathrm{F}(1,18)=54.18$, $\mathrm{p}<.001]$ and between the two stimulus sets $[\mathrm{F}(1,18)$ $=24.20, p<.001]$, as well as a significant stimulus set $\times$ group interaction $[F(1,18)=26.11, p<.001]$. A post hoc test for simple effects revealed that the significant interaction was due to the relatively poor performance of the mixed-vowel group on the Set 2 stimuli $[F(1,18)$ $=64.87, \mathrm{p}<.0011$. Recall that these Set 2 stimuli did not match the vowel quality of the original training stimuli.

These results indicate that both the constant-vowel group and the mixed-vowel group generalized their pointing response from the male adult vowel tokens to the similar vowel tokens from the other talkers. These results demonstrate 3-year-old children's perceptual constancy for natural tokens of the vowels /a/ and /i/ across talkers. Moreover, these results demonstrate that visual reinforcement for an arbitrary grouping of two vowel categories is not sufficient to overcome the natural tendency to categorize vowels by vowel quality.

\section{EXPERIMENT 2}

The results of Experiment 1 demonstrated that our twoalternative pointing task can provide a measure of perceptual constancy in 3-year-olds for the vowels /a/ and /i/ produced by several talkers. Although it was important to verify that our procedures were successful, the finding of perceptual constancy in 3-year-olds was not surprising, because analogous results had been obtained in 6-month-olds by Kuhl (1979). However, it is important to emphasize that perceptual constancy does not necessarily imply a normalization process. Both perceptual constancy and normalization involve the perceptual segregation of acoustically variable tokens into discrete categories. However, normalization is a special case of perceptual constancy in which no simple acoustic similarity underlies the perceptual segregation. As shown in Figure 1A for Kuhl's (1979) /a/-/o/ stimuli, there is a simple solution to the segregation of $/ \mathrm{a} / \mathrm{s}$ and $/ \mathrm{J} / \mathrm{s}$ within the F1-F2 vowel space. That is, all vowels with $F 1$ greater than $700 \mathrm{~Hz}$ or with F2 greater than $1100 \mathrm{~Hz}$ are members of the category /a/. As shown in Figure 1B for the $/ \mathfrak{/} / / \mathrm{\Lambda} /$ stimuli used in Experiment 2, there is no simple rule that allows for the segregation of the two perceptual categories, because there is overlap of the formant frequencies within the F1-F2 vowel space. Obviously, there must be some other acoustic information in each vowel token (e.g., F0 or F3) that enables the listener to perceive consistent vowel categories despite this formant frequency overlap. However, research on adults' vowel perception has not as yet been successful in discovering a general rule for vowel normalization based on the relations among the various formant frequencies. This failure to find a normalization rule was the impetus for the proposal that dynamic events within the syllable might provide a mechanism for solving the problem of vowel normalization (Strange et al., 1976; Verbrugge et al., 1976).

The purpose of Experiment 2 was to assess 3-year-old children's categorization of the eight vowels shown in Figure 1B. If one group presented with consistent vowel tokens was successful at the categorization task, while another group presented with inconsistent vowel tokens failed the categorization task, then we would have evidence for children's normalization of these isolated, quasisteady-state tokens of $/ æ /$ and $/ \Lambda /$. It is important to reiterate that these tokens did not contain the temporal or dynamic spectral cues, such as inherent duration or formant transitions, that are present in syllables composed of consonants and vowels. Thus, only relatively static formantfrequency information was available for the normalization process, and the children could not rely on semantic context to categorize these vowels, which contained formant frequency overlap in the F1-F2 vowel space.

\section{Method}

Subjects. The subjects were 203 -year-old children from the Bloomington, Indiana, area; their ages ranged from 2 years 11.25 months to 3 years 4.5 months, with a mean of 3 years 1 month. The children's parents were contacted following the procedures described in Experiment 1. The subjects were tested twice a week 
for a total of three to seven sessions and were paid $\$ 3$ per session. None of the subjects from Experiment 1 participated in this experiment. An additional 40 subjects were dropped, after they had completed two or more sessions, because of illness (2), scheduling conflicts (6), or inability to reach the testing criterion for this difficult contrast (32). ${ }^{3}$

Stimuli. The stimuli were tokens of the vowels $/ æ /$ and $/ \mathrm{N} /$ taken from the words "had" and "hud," produced at a slow rate of speech by the same talkers from Experiment 1. These words were recorded and digitized with the same equipment used in Experiment 1. Vowels were isolated from the words using a waveform file editor (Luce \& Carrell, 1981). These stimuli were also edited to control for duration (within one pitch period of $300 \mathrm{msec}$ ) and amplitude (63 $\pm 2 \mathrm{~dB}$ SPL), using the procedures described in Experiment 1.

Formant frequencies were measured at the midpoint of each stimulus using the same spectral analysis programs as in Experiment 1 (Carrell, 1984; Kewley-Port, 1978). The mean fundamental frequency of each token was also measured using the same program as in Experiment 1 (Smith, 1981). The first three formant frequencies and the fundamental frequency for each token are listed in Table 3 . As shown in Figure $1 \mathrm{~B}$, the tokens of $/ \mathrm{A} /$ by the female adult and the children had F1 and F2 values that are closer in frequency to the male adult's production of $/ æ / .^{4}$

Procedure. The procedure in this experiment paralleled that of Experiment 1. Ten subjects were assigned to the constant-vowel group, in which all tokens of /æ/ were reinforced by one TV and all tokens of $/ \Lambda /$ were reinforced by the other TV. Another 10 subjects were assigned to the mixed-vowel group, in which two /æ/s and two $/ \mathrm{A} / \mathrm{s}$ were paired with each TV. The pairing of TVs and vowels was counterbalanced across subjects. Representative constant-vowel and mixed-vowel stimulus sets are listed in Table 4.

As in Experiment 1, a criterion of $90 \%$ correct on 10 consecutive trials was required to proceed from the testing to the categorization phase. The results are based on the subjects' responses to 10 trials of each vowel token, or a total of 80 trials per subject. The only procedural difference from Experiment 1 was that an incorrect response led to an 8-sec delay (a time-out corresponding to the duration of reinforcement) before another trial could be in-

Table 3

Formant Frequency Values for Stimuli In Experiment 2

\begin{tabular}{|c|c|c|c|c|}
\hline Talker & FO & F1 & $\mathrm{F} 2$ & F3 \\
\hline $\begin{array}{l}\text { Male Adult } / \mathfrak{m} / \\
\text { Male Adult } / \mathbf{\Lambda} /\end{array}$ & $\begin{array}{l}115 \\
115\end{array}$ & $\begin{array}{l}704 \\
527\end{array}$ & $\begin{array}{l}1602 \\
1230\end{array}$ & $\begin{array}{l}2040 \\
2068\end{array}$ \\
\hline $\begin{array}{l}\text { Female Adult } / \mathfrak{z} / \\
\text { Female Adult } / \mathbf{\Lambda} /\end{array}$ & $\begin{array}{l}199 \\
196\end{array}$ & $\begin{array}{l}773 \\
764\end{array}$ & $\begin{array}{l}2167 \\
1636\end{array}$ & $\begin{array}{l}2795 \\
3056\end{array}$ \\
\hline $\begin{array}{l}\text { Male Child / } / 2 \text { / } \\
\text { Male Child } t_{\mathbf{\Lambda}} /\end{array}$ & $\begin{array}{l}266 \\
270\end{array}$ & $\begin{array}{r}1039 \\
822\end{array}$ & $\begin{array}{l}2118 \\
1614\end{array}$ & $\begin{array}{l}2538 \\
3096\end{array}$ \\
\hline $\begin{array}{l}\text { Female Child / } æ / \\
\text { Female Child } / \mathrm{a} /\end{array}$ & $\begin{array}{l}225 \\
242 \\
\end{array}$ & $\begin{array}{r}1088 \\
938 \\
\end{array}$ & $\begin{array}{l}1957 \\
1686 \\
\end{array}$ & $\begin{array}{l}2533 \\
3793 \\
\end{array}$ \\
\hline
\end{tabular}

Table 4

Representative Stimulus Sets for Constant- and Mixed-Vowel Groups in Experiment 2

\begin{tabular}{|c|c|}
\hline Left TV & Right TV \\
\hline \multicolumn{2}{|c|}{ Constant-Vowel Group } \\
\hline $\begin{array}{l}\text { 1. Male Adult } / æ / \\
\text { 2. Female Adult } / æ / \\
\text { 3. Male Child } / æ / \\
\text { 4. Female Child } / æ /\end{array}$ & $\begin{array}{l}\text { 5. Male Adult } / \mathrm{A} / \\
\text { 6. Female Adult } / \mathrm{N} / \\
\text { 7. Male Child } / \mathrm{A} / \\
\text { 8. Female Child } / \mathrm{N} /\end{array}$ \\
\hline \multicolumn{2}{|c|}{ Mixed-Vowel Group } \\
\hline $\begin{array}{l}\text { 1. Male Adult } / æ / \\
\text { 2. Female Child } / æ / \\
\text { 3. Female Adult } / \mathrm{N} / \\
\text { 4. Male Child } / \mathrm{N} /\end{array}$ & 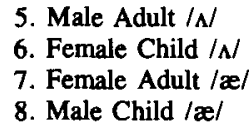 \\
\hline
\end{tabular}

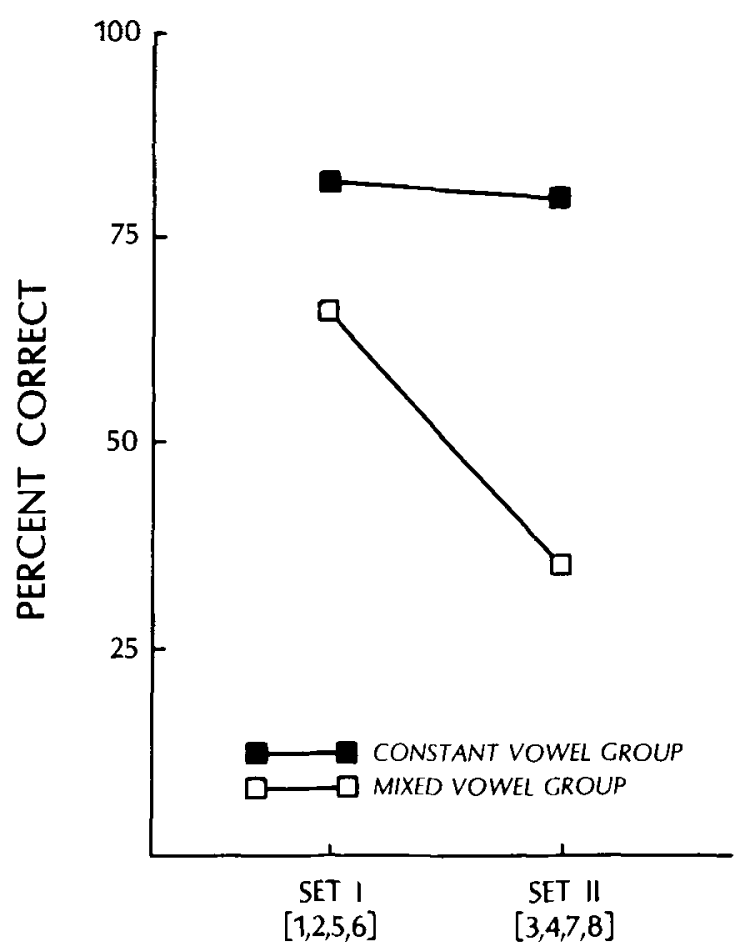

Figure 4. Mean percentage of correct responses in the constantand the mixed-vowel groups for Set 1 and Set 2 stimuli in Experiment 2.

itiated. This time-out was added to indicate more clearly that an incorrect response had been made.

\section{Results and Discussion}

Overall, subjects in the constant-vowel group responded correctly on an average of $79.9 \%$ of the trials $(S D=15.3)$, whereas subjects in the mixed-vowel group responded correctly on only $50.5 \%$ of the trials $(S D=2.9)$. As in Experiment 1 , this group difference was present even on the first trial for each of the eight vowels $(76.3 \%$ and $51.5 \%$ correct for the constant and mixed groups, respectively). Furthermore, the chance performance of the mixed-vowel group was not the result of their forgetting the appropriate pointing responses to the training stimuli after entering the categorization phase. The mean performance of the mixed-vowel group to the training stimuli presented during the categorization phase was $67.4 \%$ correct, a level that was significantly above $50 \%[t(9)=2.79, \mathrm{p}<.05]$ but not significantly different from the mean of $82.9 \%$ correct for the constant-vowel group $[\mathrm{t}(18)=1.82, \mathrm{p}>$ .05]. Finally, as shown in Figure 4, the performance of the constant-vowel group averaged $81.5 \%$ correct $(\mathrm{SD}=15.4)$ on Set 1 stimuli and $78.5 \%$ correct $(\mathrm{SD}=16.5)$ on Set 2 stimuli. In contrast, the performance of the mixed-vowel group was $66.2 \%$ correct $(S D=15.9)$ on Set 1 stimuli and 34.4\% correct $(S D=14.0)$ on Set 2 stimuli.

A two-factor, mixed-design analysis of variance with repeated measures was used to analyze these data. There 
was a significant difference between the performance of the constant- and mixed-vowel groups $[F(1,18)=30.64$, $\mathrm{p}<.001]$ and between the two stimulus sets $[\mathrm{F}(1,18)$ $=10.91, \mathrm{p}<.005]$, as well as a significant stimulus set $\times$ group interaction $[F(1,18)=9.57, p<.01]$. Post hoc tests for simple effects revealed that the difference between the constant- and mixed-vowel groups for Set 1 stimuli was not significant $[F(1,18)=3.7, p>.05]$, and that the interaction was due to the difference between the constant- and mixed-vowel groups on Set 2 stimuli $[F(1,18)=45.00, p<.001]$.

These results demonstrate that both groups generalized their pointing responses from the training stimuli to the similar vowel tokens from the other talkers, despite the overlap in F1 and F2 frequency between vowel categories. Thus, these data provide evidence of vowel normalization by 3-year-olds. This vowel normalization consists of a more sophisticated form of perceptual constancy than that demonstrated in Experiment 1 or in previous research with young infants (Kuhl, 1979, 1983).

\section{GENERAL DISCUSSION}

In both experiments, 3 -year-olds spontaneously generalized a directional response from the male adult vowel tokens to the appropriate vowels produced by a female adult and two children. In the first experiment, the subjects readily categorized the vowels /a/ and /i/ across talkers, thus demonstrating their perceptual constancy for these isolated tokens. Stimuli within vowel categories shared a similar spectral pattern, although the absolute frequencies differed. These vowels were categorized by vowel quality even by subjects in the mixed-vowel group, who were reinforced for responding to the stimuli in a different way. This suggests that vowel quality was a particularly salient dimension despite the variation in other aspects of the stimuli, such as voice quality and fundamental frequency.

Similar results were obtained in the second experiment for the isolated, quasi-steady-state tokens of the vowels $/ æ /$ and $/ \Lambda /$. These vowels were chosen specifically because of the formant frequency overlap between the male adult's $/ æ /$ and the other talkers' productions of $/ \mathrm{\Lambda} /$. Despite this overlap within the F1-F2 vowel space, subjects categorized the female adult and the two children's

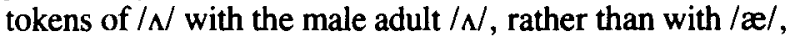
which contained more similar F1 and $F 2$ frequencies. Of particular importance is that this pattern of results held for the mixed-vowel group, which was not reinforced for categorizing the vowels by vowel quality. Taken together, these results demonstrate that steady-state formant information was sufficient for vowel normalization in 3year-olds.

Although 3-year-olds clearly have mastered many aspects of receptive and productive language, it was not clear prior to Experiment 2 whether vowels in isolation could be normalized without some initial exposure to the test stimuli. The results for the very first trials with each of the eight vowels indicated that by 3 years of age children can correctly normalize the spectrally similar vowels $/ æ /$ and $/ \Lambda /$ without relying on dynamic cues, semantic information, or listening experience with tokens produced by a particular vocal tract to recalibrate the vowel space. What remains unclear is (1) the mechanism underlying vowel normalization in children and adults, and (2) the process by which this normalization mechanism develops. Research on adults' vowel perception indicates that no simple relational rule among the formants is effective in appropriately transforming the vowel space to render discrete vowel categories, although some higher level acoustic information must be present in the vowels produced by different talkers to enable the normalization process. Finally, the developmental aspect of vowel normalization must await objective tests, analogous to those employed in the present study, of infants and younger children.

\section{REFERENCES}

AbBS, M.S., \& Minifie, F.D. (1969). Effect of acoustic cues in fricatives on perceptual confusions in preschool children. Joumal of the Acoustical Society of America, 46, 1535-1542.

Aslin, R. N., Perey, A. J., Hennessy, B. L. , \& Pisoni, D. B. (1977, December). Perceprual analysis of speech sounds by prelinguistic infants: A first report. Paper presented at the meeting of the Acoustical Society of America, Miami.

Aslin, R. N., Pisoni, D. B., \& JusczyK, P. W. (1983). Auditory development and speech perception in infancy. In M. M. Haith \& J. J. Campos (Eds.), Infancy and developmental psychobiology [Vol. 2 of P. Mussen (Ed.), Handbook of child psychology]. New York: Wiley. Assmann, P. F., Nearey, T. M., \& Hogan, J. T. (1982). Vowel identification: Orthographic, perceptual, and acoustic aspects. Joumal of the Acoustical Society of America, 68, 975-989.

BERNACKI, B. (1981). WAVMOD: A program to madify digital waveforms (Progress Report No. 7). Bloomington: Indiana University, Speech Research Laboratory.

CARRE LL, T. D. (1984). The effects of fundamental frequency, formant spacing, and glottal waveform on the perception of talker identity. Unpublished doctoral dissertation, Indiana University.

Delattre, P., Liberman, A. M., Cooper, F. S., \& Gerstman, L. J. (1952). An experimental study of the acoustic determinants of vowel color: Observations on one-and two-formant vowels synthesized from spectrographic patterns. Word, 8, 195-210.

Diehl. R. L.. MCCusker, S. B., \& Chapman, L. S. (1981). Perceiving vowels in isolation and in consonantal context. Journal of the Acoustical Society of America, 69, 239-248.

Eimas, P. D., \& Miller, J. L. (1980). Discrimination of the information for manner of articulation. Infant Behavior and Development, 3, 367-375

Gerstman, L. J. (1968). Classification of self-normalized vowels. IEEE Transactions on Audio- and Electroacoustics, AU-16, 78-80.

Gottfried, T., \& STRANGe, W. (1980). Identification of coarticulated vowels. Journal of the Acoustical Society of America, 68, 1626-1635.

GREENLEE, M. (1978). Leaming the phonetic cues to the voiced-voiceless distinction: An exploration of parallel processes in phonological change. Unpublished doctoral dissertation, University of California, Berkeley

GREENLEE. M. (1980). Leaming the phonetic cues to the voiced-voiceless distinction: A comparison of child and adult speech perception. Joumal of Child Language. 7. 459-468.

Hillenbrand, J. (1983). Perceptual organization of speech sounds by infants. Journal of Speech and Hearing Research, 26, 268-282.

Jenkins, J. J., Strange, W., Edman, T. R. (1983). Identification of vowels in "vowelless" syllables. Perception \& Psychophysics, 34, 441-450. 
Joos, M. A. (1948). Acoustic phonetics. Language Supplement, 2, 1-136. Jusczyk, P. W., Pisoni, D. B., Walley, A., \& Murray, J. (1980). Discrimination of relative onset time of two-component tones by infants. Journal of the Acoustical Society of America, 67, 262-270.

KATZ, J., JusczYK, P. W. (1980, April). Do six-month-old infants have perceptual constancy for phonetic segments? Paper presented at the International Conference on Infant Studies, New Haven, Connecticut.

KEWLEY-PORT, D. (1978). SPECTRUM: A program for analyzing the spectral properties of speech (Progress Report No. 5). Bloomington: Indiana University, Speech Research Laboratory.

KraUSE, S. E. (1982). Vowel duration as a perceptual cue to postvocalic consonant voicing in young children and adults. Joumal of the Acoustical Society of America, 71, 990-995.

KuHL, P. K. (1979). Speech perception in early infancy: Perceptual constancy for spectrally dissimilar vowel categories. Journal of the Acoustical Society of America, 66, 1668-1679.

KUHL, P. K. (1983). Perception of auditory equivalence classes for speech in early infancy. Infant Behavior and Development, 6, 263-285.

KUHL, P. K., MilleR, J. D. (1982). Discrimination of auditory target dimensions in the presence or absence of variation in a second dimension by infants. Perception \& Psychophysics, 31, 279-292.

LIEBERMAN, P. (1973). On the evolution of language: A unified view. Cognition, 2, 59-94.

LuCE, P. A., Carrell, T. D. (1981). Creating and editing waveforms using WAVES (Progress Report No. 7). Bloomington: Indiana University, Speech Research Laboratory.

MACCHI, M. (1980). Identification of vowels spoken in isolation versus vowels spoken in consonantal context. Journal of the Acoustical Society of America, 68, 1636-1642.

MilleR, J. L., \& EIMAs, P. D. (1979). Organization in infant speech perception. Canadian Journal of Psychology, 33, 353-367.

Nearey, T. M. (1977). Phonetic feature systems for vowels. Unpublished doctoral dissertation, University of Connecticut.

NeAREY, T. M. (1983). Vowel-space normalization procedures and phone-preserving transformation of synthetic vowels. Journal of the Acoustical Society of America, Supplement 1, 74, S17.

PARKer, E. M., \& DIEHL, R. L. (1984). Identifying vowels in CVC syllables: Effects of inserting silence and noise. Perception \& Psychophysics, 36, 369-380.

Peterson, G. E., * Barney, H. L. (1952). Control methods used in a study of the vowels. Journal of the Acoustical Society of America, 24, 175-184.

Shankweiler, D. P., Strange, W., \& Verbrugge, R. R. (1977) Speech and the problem of perceptual constancy. In R. E. Shaw \& J. Bransford (Eds.), Perceiving, acting and knowing: Toward an ecological psychology. Hillsdale, NJ: Erlbaum.

Simon, C., Fourcin, A. J. (1978). Cross-language study of speechpattern learning. Journal of the Acoustical Society of America, 63, 925-935.

SMITH, T. S. (1981). Programs implementing the SIFT (Simple Inverse Filter Tracking) pitch extraction algorithm, as described by J. Markel. Unpublished manuscript, Indiana University.

Strange, W., \& Broen, P. A. (1981). The relationship between perception and production of $/ w /, / r /$, and $/ / /$ by three-year-old children. Journal of Experimental Child Psychology, 31, 81-102.

Strange, W., Edman, T. R., \& Jenkins, J. J. (1979). Acoustic and phonological factors in vowel identification. Journal of Experimental Psychology: Human Perception and Performance, 5, 643-656.

StRanGE, W., \& GotTFrIED, T. (1980). Task variables in the study of vowel perception. Journal of the Acoustical Society of America, 68, 1622-1625.
Strange, W., Jenkins, J. J., \& Johnson, T. L. (1983). Dynamic specification of coarticulated vowels. Journal of the Acoustical Society of America, 74, 695-705.

Strange, W., Verbrugge, R. R., Shankweiler, D. P., \& Edman, T. R. (1976). Consonant context specifies vowel identity. Journal of the Acoustical Society of America, 60, 213-224.

Verbrugge, R. R., Strange, W., Shankweiler, D. P., \& Edman, T. R. (1976). What information enables a listener to map a talker's vowel space? Journal of the Acoustical Society of America, 60, 198-212.

\section{NOTES}

1. An earlier study by Abbs and Minifie (1969) used a referent-free, two-alternative, buttonpressing task with 3- to 5-year-old children. However, their procedure was used to test fricative discrimination in an ABX paradigm, and thus did not assess categorization.

2. This $46 \%$ attrition rate is similar to the $40 \%-60 \%$ rate typical of studies using the well-established high-amplitude sucking (HAS) procedure with infants (see Eimas \& Miller, 1980; Jusczyk, Pisoni, Walley, \& Murray, 1980; Miller \& Eimas, 1979), as well as the $40 \%$ rate reported by Krause (1982) in another two-alternative task with 3year-olds.

3. This $67 \%$ attrition rate is admittedly high, perhaps for the following reasons. First, contrasts involving spectrally similar vowels, such as $/ æ /-/ / /$ or $/ \mathrm{a} /-/ \mathrm{J} /$, are considerably more difficult to discriminate than spectrally dissimilar vowels, such as /a/-/i/ (Kuhl, 1983; Miller \& Eimas, 1979). Second, the two-alternative pointing task involves learning an initially arbitrary association between stimuli and responses. If the child adopts a strategy of randomly directed pointing responses, then reinforcement will be obtained on half of the trials. This rather lax criterion for receiving reinforcement is apparently sufficient on this task for a significant proportion of 3-year-olds. Finally, the lower attrition rate of other studies using two-alternative procedures with preschoolers may be due in part to methodological differences. For example, in Simon and Fourcin's (1978) study, a testing criterion on endpoint stimuli either was not used or was omitted from the procedural description. Another study, which did employ a strict pretest criterion (Strange \& Broen, 1981), allowed a trial to be repeated under certain circumstances, for example, if a child did not respond or made a bidirectional response. In our study, this type of trial was treated as an incorrect response, thereby making it more difficult to meet the $90 \%$ correct criterion in the testing stage. Thus, the rigid scoring criterion used in the present study, along with the difficult $/ æ /-/ \mathrm{A} /$ contrast, led to a relatively high attrition rate. However, it was essential to determine that each subject was categorizing the training stimuli extremely accurately before an attempt was made to introduce additional vowels in the categorization phase.

4. Although the formant frequencies listed in Table 3 were taken only from the midpoint of each vowel token, these values were quite representative of the steady state (middle $200 \mathrm{msec}$ ) of each token. Because the tokens were extracted from natural speech, there were some dynamic changes in formant frequency (typically a $50-$ to $100-\mathrm{Hz}$ rise in $\mathrm{F} 1$ during the initial $50 \mathrm{msec}$ and a slight fall in $\mathrm{F} 1$ and $\mathrm{F} 2$ during the final $50 \mathrm{msec}$ ). However, these dynamic changes in F1 and F2 would not alter the pattern of formant frequency overlap illustrated in Figure 1B.

(Manuscript received December 14, 1984; revision accepted for publication February 6, 1985.) 